\title{
The Demand for Pediatric Care: An Hedonic Approach
}

\section{Fred Goldman}

\author{
Columbia University School of Public Health and National Bureau of Economic Research
}

\section{Michael Grossman}

City University of New York Graduate School and National Bureau of Economic Research

\begin{abstract}
When the quality of a good varies, quantity in physical units may be a very misleading measure of total consumption. In this paper it is argued that differences in quality are a distinguishing feature of the market for physicians' services. We develop a model to analyze properties of demand functions for the quantity and quality of physicians' services and apply the model to study the demand for pediatric care-physicians' services rendered to children. The theoretical model of quantity-quality substitution provides a framework for demand analysis whenever the market for a good is distinguished by a quality component.
\end{abstract}

When the quality of a good varies, quantity in physical units may be a very misleading measure of total consumption. This point long has been

This is a condensed version of Goldman and Grossman (1976). The longer version is available on request. Grossman's research was supported by PHS grant 5-P01-HS00451 from the National Center for Health Services Research, Health Resources Association, to the National Bureau of Economic Research. Goldman's research was supported by PHS grant R01-HS02562 from the National Center for Health Services Research, HRA, to Columbia University School of Public Health. A preliminary version of this paper was presented at the fiftieth annual conference of the Western Economic Association, San Diego, California, June 1975. We owe a special debt to Ann Dukes Colle for discussing in detail many points in the paper with us and for providing us with "high-powered" computer programming assistance. We also would like to thank Gary S. Becker, Barry R. Chiswick, Linda Nasif Edwards, Isaac Ehrlich, Martin Feldstein, Victor R. Fuchs, Malcolm Galatin, Gilbert R. Ghez, Donald F. Gordon, Reuben Gronau, Lee Lillard, Robert Lipsey, Robert T. Michael, Sam Peltzman, Anne D. Williams, Robert J. Willis, and a referee for helpful comments and suggestions; Kathleen V. McNally and Christine Wilson for research assistance; and Rowland L. Mindlin, M.D., for generously making the data available for this study. This paper has not yet undergone the review accorded official NBER publications; in particular, it has not yet been submitted for approval by the Board of Directors.

[Journal of Political Economy, 1978, vol. 86, no. 2, pt. 1]

(C) 1978 by The University of Chicago. All rights reserved. 0022-3808/78/8602-0004\$01.79 
recognized in the literature on hedonic price functions and has served as the rationale for estimates of the quality of automobiles and houses based on the imputed value of these goods. ${ }^{1}$ In this paper it is argued that differences in quality are a distinguishing feature of the market for physicians' services. Quality differences among physicians can be traced in turn to their different levels of investment in human capital. For instance, medical schooling, internships, and residency training programs can differ in quality; and physicians may or may not obtain board certification in a specialty, faculty status, and memberships in peer professional societies. Not only do consumers choose physicians from among a broad array of physician quality, they also may substitute quality for quantity in the production of medical services in particular and health in general.

The model that we develop below is used to analyze properties of the demand functions for quantity and quality. It is then applied to study the demand for pediatric care-physicians' services rendered to children. ${ }^{2}$ The theoretical model of quantity-quality substitution provides a framework for demand analysis whenever the market for a good is distinguished by a quality component. The analysis is developed within the household production framework of consumer behavior and assumes that parents both demand and produce quality children, where children's health is one aspect of their quality. Thus, the demand curves for pediatric care are derived from the interaction between the demand and production functions of children's health. In the analysis, we emphasize the effects of income, the price of pediatric services, and the time costs of obtaining these services on the quantity (measured in terms of visits) and quality of services demanded.

The strategy of fitting separate demand curves for quality and visits has not been pursued in existing studies of the demand for physicians' services. Instead, one finds in these studies either biased estimates of the visit equation or estimates of demand functions in which the dependent variable is number of visits multiplied by a proxy for quality. ${ }^{3}$ These procedures do not distinguish between the quality and visit demand curves that we emphasize. In particular, we demonstrate theoretically and empirically that the ratio of quality to visits varies with income and with the physician fee and time price components of pediatric care. Thus, in analyzing the impact of government policies such as direct cash subsidies, national health

${ }^{1}$ See, for example, Griliches 1961; Muth 1969; Cowling and Rayner 1970; Griliches 1971; Triplett 1971; Rosen 1974; King 1975; Ohta and Griliches 1975; and Straszheim 1975.

2 Our model of the demand for quantity and quality is an extension of work by Houthakker (1952-53); Theil (1952-53); and especially Becker and Lewis (1973).

${ }^{3}$ See, for example, Fuchs and Kramer.1972; Grossman 1972; Newhouse and Phelps 1974, 1976; Holtmann and Olsen 1974; Acton 1975, 1976; Feldman 1975; Phelps 1975; and Inman 1976. 
insurance, or reductions in travel and waiting time via increases in the supply of medical practitioners, it is important to account for the separate effects of these policies on the demand for visits and quality.

\section{The Model}

\section{A. Analytical Framework}

Let the utility function of parents be given by

$$
\Psi=\Psi(h, z),
$$

where $h$ stands for child health and $z$ stands for all other commodities in the utility function and may be interpreted as parents' standard of living. The production function of child health has as inputs number of visits to physicians $(v)$, quality per visit $(q)$, and vector of additional variables $(y):^{4}$

$$
h=h(v, q, y) .
$$

Here, quality per visit is assumed to be the same for all visits by a given family. Arguments in the $y$ vector include genetic endowment and age of the child, parental characteristics such as level of schooling, and random variations in health due to, say, illness.

The quality variable in the production function is assumed to measure variations in productivity among physicians. These variations reflect experience, vintage, and model effects commonly found in the literature on hedonic price functions. Quality and visits enter the production function as separate variables, so that pediatric services depend on $q$ and $v$ but are not simply given as the product of these two variables. ${ }^{5}$ Substitution of equation (2) into equation (1) yields a derived utility function of the form

$$
U=U(v, q, z)
$$

4 The model is static, and it is assumed that the year is the relevant period of time throughout the analysis. For models of child health that emphasize intertemporal considerations, see Friedman and Leibowitz (1975) and Grossman (1975). In the context of a life-cycle model, it is natural to think of $h$ as the stock of health, but the stock concept is not important for the analysis in this paper. In a more complete specification of the production function, length of time spent by the physician with the patient per visit would be an additional input. For a theoretical analysis of the role of this input, see Goldman and Grossman (1976).

5 The above treatment follows Becker and Lewis (1973) and Willis (1973), who assume that number of children and quality per child are separate variables in the parents' utility function. More generally, Houthakker (1952-53) and Theil (1952-53) make this assumption with regard to the quality and quantity of any good. In addition, Rosen (1968) postulates that the labor input demanded by firms depends on employment and hours per person, but that this input is not simply the product of employment and average hours. 
where the exogenous $y$ vector has been suppressed for simplicity. Note that $v$ and $q$ are separate variables in the derived utility function because they are separate variables in the health production function.

Parents maximize utility subject to a "full" income budget constraint. To develop the nature of this constraint, let $p v$ denote expenditures in terms of payment to the physician for pediatric services, where $p$ is the average price of a visit. Price and total expenditures depend on quality. In particular,

$$
p=\hat{p} q, \quad \frac{\partial^{2} p}{\partial q^{2}}=0
$$

Hence $\hat{p}$ is the given (quality-adjusted) price of one unit of $v q$.

Expenses in addition to $\hat{p} v q$ are required to obtain pediatric care because of transportation costs ( $c$ dollars per visit) and travel time ( $t_{1}$ hours per visit) that must be incurred to reach the physician's office and return and waiting time in the office ( $t_{2}$ hours per visit). Since the mother typically is responsible for taking the child to the physician, the opportunity cost of 1 hour of travel and waiting time is evaluated at her hourly wage rate (w). The sum of foregone earnings per visit and transportation cost per visit may be interpreted as the "fixed cost" of a visit (cost that is independent of quality) $:^{6}$

$$
f=c+w\left(t_{1}+t_{2}\right) .
$$

If the price of $z=\$ 1.00$, the budget constraint may be written as

$$
S=z+\hat{p} v q+v\left(w t_{1}+w t_{2}+c\right) \text {. }
$$

According to equation (6), outlays on $q, v$, and $z$ exhaust full income $(S)$, defined as family property (nonearnings) income plus husband's earnings plus wife's earnings when all of her available time is allocated to the market.

First-order conditions for the optimal amounts of $z, q$, and $v$ are

$$
\begin{gathered}
u_{z}=\lambda, \\
u_{q}=\lambda \hat{p} v,
\end{gathered}
$$

and

$$
u_{v}=\lambda(\hat{p} q+f)
$$

6 Throughout the analysis it is assumed that there is no fixed cost of quality (cost that is independent of visits). Such a cost would arise if consumers had imperfect information about the quality of pediatric care and allocated time to the acquisition of information about quality. The weaker assumption that the fixed cost of quality is small relative to that of visits would not modify the basic analysis. In Section II, search to acquire information about quality-adjusted price $(\hat{p})$ is introduced and analyzed, although this search process does not introduce a fixed cost of quality. 
where $u_{i}(i=z, q, v)$ is the marginal utility of the $i$ th argument in the utility function and $\lambda$ is the marginal utility of income. Equations (8) and (9) contain definitions of the "shadow prices" of quality and visits:

$$
\begin{gathered}
\pi_{q}=\hat{p} v, \\
\pi_{v}=\hat{p} q+f .
\end{gathered}
$$

As Becker and Lewis (1973) emphasize, the shadow price of quality rises with visits, and the shadow price of visits rises with quality. In equilibrium the marginal rate of substitution between quality and visits must equal the price of quality relative to the price of visits:

$$
\frac{u_{q}}{u_{v}}=\frac{\pi_{q}}{\pi_{v}}=\frac{\hat{p} v}{\hat{p} q+f} \text {. }
$$

Condition (12) is used to examine the effects of changes in income, fixed cost, and quality-adjusted price on the equilibrium amounts of quality and visits.

\section{B. Comparative Static Analysis}

Based on the above framework, the structural demand curves for quality and number of pediatric visits are as follows:

$$
\begin{aligned}
& E v=\eta_{v} E(R / \pi)-\left(1-k_{v}\right) \bar{\sigma}_{v} E \pi_{v}+k_{q} \sigma_{v q} E \pi_{q}, \\
& E q=\eta_{q} E(R / \pi)+k_{v} \sigma_{v q} E \pi_{v}-\left(1-k_{q}\right) \bar{\sigma}_{q} E \pi_{q},
\end{aligned}
$$

where the symbol $E$ denotes the logarithmic differential operator $d \ln$. Definitions of all other symbols in equations (13) and (14), as well as additional symbols that are used in the comparative static analysis, are given in table 1 . Since the shadow prices of quality and visits are endogenous, the framework also contains the following reduced-form demand curves:

$$
\begin{aligned}
& E v=\bar{\eta}_{v} E S+\bar{\phi}_{v} E f+\bar{\varepsilon}_{v} E \hat{p}, \\
& E q=\bar{\eta}_{q} E S+\bar{\phi}_{q} E f+\bar{\varepsilon}_{q} E \hat{p} .
\end{aligned}
$$

As Becker and Lewis (1973) stress, reduced-form income elasticities might differ significantly from structural income elasticities in a model in which consumers can trade quality and quantity. Structural or "pure" income elasticities are obtained by varying income evaluated at shadow prices $(R)$, with shadow prices and, therefore, a price level of shadow prices $(\pi)$ held constant. On the other hand, reduced form or "observed" income elasticities are obtained by varying money full income $(S)$, with quality-adjusted price $(\hat{p})$ and fixed cost per visit $(f)$ held constant. One source of the difference between the two sets of elasticities is that a 1 percent increase in $S$ will increase real income evaluated at shadow prices 


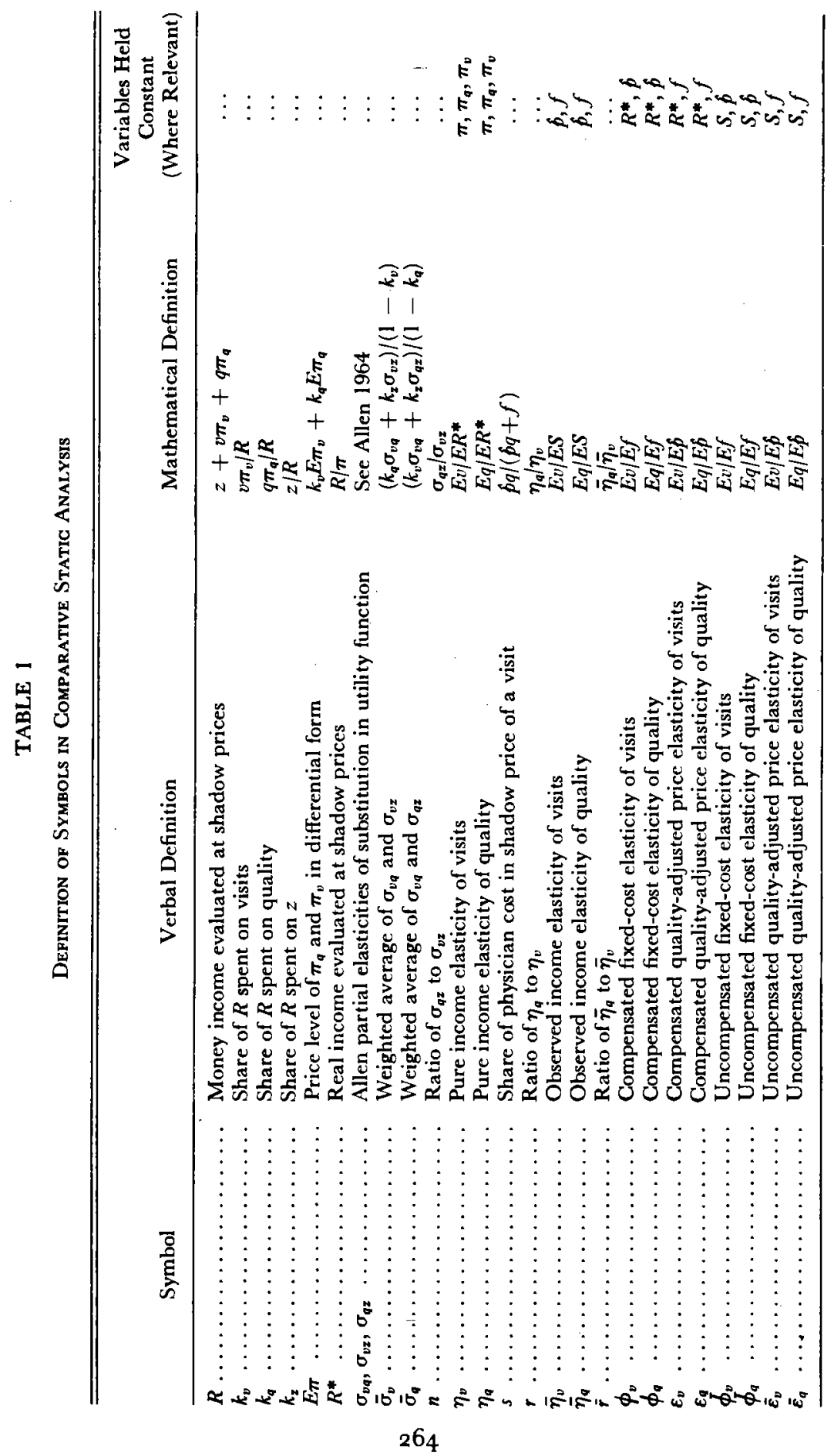


TABLE 2

Comparative Static Formulas

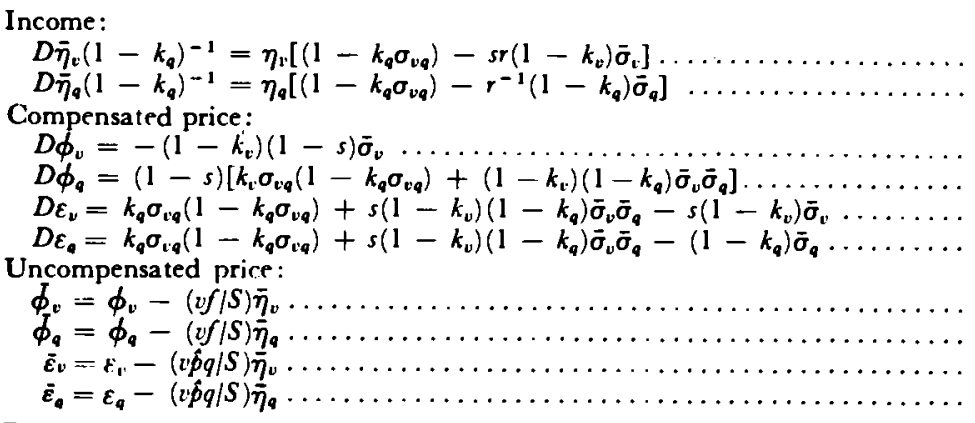

Note. $-D=\left(1-k_{q} \sigma_{v q}\right)^{2}-k_{v}-1 k_{q}\left(1-k_{v}\right) \sigma_{v}\left(1-k_{q}\right) \sigma_{q}$. Note that $D$ and $\left(1-k_{q} a_{v q}\right)$ must begreater than zero by the second-order conditions for the maximization of utility. Note also that $\tilde{\sigma}_{v}$ is a weighted average of the Allen partial elasticities of substitution in the utility function between $v$ and $q$ and between $\nu$ and $z\left(\sigma_{v q}\right.$ and $\left.\sigma_{v z}\right)$. Similarly, $\delta_{q}$ is a weighted average of $\sigma_{v q}$ and $\sigma_{q z}$, and both $\delta_{v}$ and $\delta_{q}$ are positive by definition.

$(R / \pi)$ by only $1-k_{q}$ percent, where $k_{q}$ is the share of $q$ in $R$. This factor reflects the dependence of the shadow price of quality on visits and the dependence of the shadow price of visits on quality. A potentially more important source of the difference between pure and observed income elasticities is that the relative price of quality $\left(\pi_{q} / \pi_{v}\right)$ could vary with $S$.

Formulas (17) and (18) in table 2 show how the observed income elasticities are related to the pure income elasticities. From these formulas the ratio of observed income elasticities $\left(\bar{r}=\bar{\eta}_{q} / \bar{\eta}_{v}\right)$ would equal the corresponding ratio of pure income elasticities $\left(r=\eta_{q} / \eta_{v}\right)$ if ${ }^{7}$

$$
r=(1 / s)=\mathrm{n},
$$

where $s$ is the share of physician cost in the shadow price of a visit $[s=\hat{p} q$ / $(\hat{p} q+f)]$ and $n$ is the ratio of the subscripted Allen partial elasticities of substitution in consumption $\left(n=\sigma_{q z} / \sigma_{v z}\right)$. When the production function is homothetic, $r$ exceeds $\dot{r}_{.}^{8}$ Even if the pure income elasticity of quality

${ }^{7}$ From (17) and (18), $\bar{r}=r\left[\left(1-k_{q} \sigma_{v q}\right)-r^{-1}\left(1-k_{q}\right) \bar{\sigma}_{q}\right] /\left[\left(1-k_{q} \sigma_{v q}\right)-s r\left(1-k_{v}\right) \bar{\sigma}_{v}\right]$. Hence, $i \geqslant r$ as $k_{q} \sigma_{i q q}[(1 / s r)-r s]+k_{z} \sigma_{v i}[(n i r)-s r]<0$. In obtaining this condition, we use the relationship between $k_{q}$ and $k_{v}: k_{q}=s k_{v}$, which can be derived by noting $k_{q} / k_{v}=q \pi_{q} / v \pi_{v}=q \hat{b}_{v} /[v(\hat{\phi} q+f)]=\hat{\phi} q /(\hat{\phi} q+f)=s$. In analyzing the relationship between $r$ and $\dot{r}$, we assume that $\sigma_{v q}, \sigma_{q}$ and $\sigma_{k z}$ are positive. It is well known that at least two of these partial elasticities of substitution must be positive. Condition (27) for equality between $r$ and $\bar{r}$ is sufficient but not necessary.

"The utility function in our model is "weakly separable" in $v$ and $q$. Given separability, $r$ and $n$ would equal unity if the production function were homothetic, and $\bar{r}$ would be smaller than $r$ (see Goldman and Uzawa 1964 and Muth 1966). Note that the formulas in the text of Section II (in notes 7, 9) are not derived under the assumption that the utility function is weakly separable. Thus, the formulas are more general than those that would obtain under the assumption of weak separability. 
exceeded that of visits, the presence of a fixed-cost component in the total cost of a visit would cause the relative price of quality to rise with income as long as $r$ were less than $1 / s$. Here a substitution effect in favor of $v$ and away from $q$ would accompany a seemingly pure change in money income.

In addition to quality and visits, the relative price of quality depends on the quality-adjusted price of pediatric care $(\hat{p})$ and the fixed cost of a visit $(f)$. An increase in $\hat{p}$ increases the shadow prices of both quality and visits. The percentage increase in the shadow price of quality would, however, exceed that of visits due to the presence of the fixed-cost component in the total cost of a visit. Thus, the relative price of quality would rise with $\hat{p}$, and consumers would substitute away from quality and toward visits. Of course, the price of visits would rise relative to the price of parents' standard of living, so that $v$ would fall relative to $z$. Although visits need not rise absolutely, the ratio of visits to quality would be positively related to quality-adjusted price. A rise in the fixed cost of a visit would cause the relative price of quality to fall and would lead consumers to substitute quality for visits. Consequently, the variables $f$ and $\hat{p}$ would have opposite effects on the demand for quality. In addition, visits would be more sensitive to a percentage change in fixed cost than an identical percentage change in quality-adjusted price.

The preceding predictions pertain to compensated (utility or real income constant) fixed cost and quality-adjusted price elasticities of visits and quality. These elasticities are given by equations (19)-(22), in table 2 . It follows that the compensated fixed-cost elasticity of visits $\left(\phi_{v}\right)$ is negative. Additionally, under fairly weak restrictions, the compensated fixedcost elasticity of quality $\left(\phi_{q}\right)$ is positive, the absolute value of the compensated quality-adjusted price elasticity of quality $\left(\varepsilon_{q}\right)$ exceeds that of visits $\left(\varepsilon_{v}\right)$, and the absolute value of $\phi_{v}$ exceeds that of $\varepsilon_{v} \cdot{ }^{9}$ Instead of analyzing compensated price elasticities that hold utility or real income evaluated at shadow prices $\left(R^{*}=R / \pi\right)$ constant, one can analyze uncompensated price elasticities that hold money full income constant (see eqq. [23]-[26] in table 2). Given estimates of the uncompensated elasticities, the observed income elasticities, and the shares of total fixed cost and total pediatric cost in income, one can use these formulas to solve for the compensated price elasticities. Such computations are made in Section III below.

9 According to equation (20), the compensated fixed-cost elasticity of quality $\left(\phi_{q}\right)$ is positive given the weak restriction that visits and quality are net substitutes $\left(\sigma_{i q}>0\right)$. We impose this restriction in our analysis of substitution effects. The signs of the compensated quality-adjusted price elasticity of visits and quality $\left(\varepsilon_{\mathrm{r}}\right.$ and $\left.\varepsilon_{q}\right)$ are ambiguous, although Theil (1952-53) shows that the sum of these two elasticities must be negative. From equations (21) and (22), the difference between $\varepsilon_{v}$ and $\varepsilon_{q}$ is

$$
D\left(\varepsilon_{v}-\varepsilon_{q}\right)=k_{v}\left(1-s^{2}\right) \sigma_{v q}+k_{z} \sigma_{v z}(n-s) .
$$

Since $s$ is less than one, the first term on the right-hand side of this equation must be 
In summary, the comparative static analysis shows that the reducedform demand curve for visits has very different properties than the reducedform demand curve for quality. In percentage terms, the responsiveness of visits to income exceeds that of quality, visits fall and quality rises as the fixed cost of a visit rises, and quality-adjusted price increases have a larger negative impact on quality than on visits. Due to these significant variations in parameters between the two demand curves, it is crucial to obtain separate estimates of each. Suppose, for example, that the quality-adjusted price faced by consumers were to decline due to the enactment of national health insurance. According to our analysis, this would increase demand for services from "high-quality" physicians (specialists) relative to "lowquality" physicians (general practitioners). Consequently, in analyzing the effect of national health insurance on the cost of physicians' services, one would have to take account of these shifts in demand for various kinds of physicians.

\section{Empirical Implementation of the Model}

The data source used to estimate demand functions for the quantity and quality of pediatric care is the Mindlin-Densen (MD) study, titled "Medical Care of Infants and Preschool Children." This is a longitudinal and cross-sectional survey covering 21 months in the period 1965-66. Geographically, the MD study encompasses two contiguous health districts in the Bronx, New York City-Mott Haven and Westchester. ${ }^{10}$ The key variables in the MD survey are annual number of office visits to physicians by the sample children, characteristics of those physicians, and their usual fees. Characteristics of physicians are available because mothers were

positive. (iven a weakly scparable utility function in $z^{\prime}$ and $q$ and a homothetic production function, $n$ would equal one, so that the second term on the right-hand side also would be positive. More generally, the equation would be positive unless $n$ were much smaller than $s$ (unless $\sigma_{q z}$ were much smaller than $\sigma_{v z}$ ). To compare the responsiveness of visits to fixed cost with its responsiveness to quality-adjusted price, subtract eq. (21) from eq. (19) :

$$
D\left(\phi_{v}-\varepsilon_{v}\right)=-k_{q} \sigma_{v q}\left(1-k_{q} \sigma_{v q}\right)-s\left(1-k_{v}\right)\left(1-k_{q}\right) \bar{\sigma}_{v} \bar{\sigma}_{q}+(2 s-1)\left(1-k_{v}\right) \bar{\sigma}_{v} .
$$

The first two terms on the right-hand side of this equation are negative, and the third term is nonpositive if $s \leq 1 / 2$. Thus, the absolute value of the difference between $\phi_{1}$ and $\varepsilon_{r}$ would be positive given $s \leq 1 / 2$ and might be positive even if $s>1 / 2$. For
$s>1 / 2$, the sign of the difference between $\phi_{v}$ and $\varepsilon_{v}$ is ambiguous because a 1 percent increase in $\hat{\phi}$ would cause a larger percentage increase in the shadow price of a visit $\left(\pi_{v}=\hat{p} q+f\right)$ than would a 1 percent increase in $f$. Since, however, an increase in $\hat{\phi}$ raises the shadow price of quality $\left(\pi_{q}=\hat{p} v\right)$, while an increase in $f$ does not, we view the case in which $\left|\varepsilon_{1}\right|>\left|\phi_{i}\right|$ as an unlikely one.

10 The study was conducted by Paul Densen, then Deputy Administrator, New York City Health Services Administration, and Rowland L. Mindlin, M.D., then Assistant Commissioner of Health, Bureau of Maternal and Child Health, New York City Department of Health. For complete descriptions of the study, see Goldman (1975) and Goldman and Grossman (1976). 
asked to identify by name all physicians in private practice who examined their children during the study period. Information on these physicians was obtained from the American Medical Association and New York State medical directories. If a source of pediatric care other than a physician in private practice was reported, the physician who rendered the care was not identified. We emphasize the demand for private pediatric care, measured by office visits and quality per visit, and include in the empirical analysis only those families whose children used at least one private-care source.

Customarily, one would assume no variation in quality-adjusted price in a cross section, particularly when all its members live in the same city. The existence of imperfect information due to costs of search is, however, a basic characteristic of the medical care market and therefore a basic source of cross-sectional variation in the quality-adjusted price of pediatric care. ${ }^{11}$ Since equilibrium search time increases and equilibrium qualityadjusted price decreases as quality and visits increase, it would be inappropriate to estimate demand functions by ordinary least squares. ${ }^{12}$ Consequently, the demand functions in Section III are fitted by two-stage least squares, with quality-adjusted price treated as an endogenous variable.

The econometric methodology that is used to estimate quality and quality-adjusted price may be outlined as follows. Begin with the defini-

11 A related source of quality-adjusted price variation is the existence of a trade-off between money price and waiting time. Since the implications of this type of price variation are similar to those due to imperfect information, we do not deal with the money price-waiting trade-off. For analyses that emphasize this trade-off, see Nichols, Smolensky, and Tideman (1971); and Acton (1975, 1976). For evidence in support of the cost-ofsearch hypothesis, see Newhouse and Sloan (1972). Using New York City data, they report a coefficient of variation of 33 percent for the fee of a first visit to a general practitioner and a coefficient of variation of 22 percent for the fee of a first visit to an internist. Coefficients of variation for fees of subsequent visits are 20 and 23 percent, respectively. For a good summary of sources of price variation in the medical care market, see Newhouse and Phelps (1974). One source mentioned by these authors, the existence of health insurance, is treated in our empirical work but is not discussed here.

12 Formally, to take account of the endogeneity of quality-adjusted price, let the price function be $p=q \hat{\phi}(T, K, u)$, where $T$ is the total amount of time spent in search, $K$ is a vector of exogenous variables whose arguments include efficiency in search and the initial or preexisting amount of information about the pediatric care market, and $u$ is a vector of unmeasured determinants of $\hat{\phi}$ or a disturbance term. By allocating more time to search activities, consumers can find lower quality-adjusted prices $(\partial \hat{p} / \partial T<0)$. They would maximize the following Lagrange function with respect to $z, q, v$, and $T: L=$ $U(v, q, z)+\lambda(S-\hat{p} v q-v f-w T)$. First-order conditions are $u_{z}=\lambda, u_{q}=\lambda \hat{p} v$, $u_{v}=\lambda(\hat{\phi} q+f)$, and $-q v(\partial \hat{p} / \partial T)=w$. With $w, K$, and $u$ held constant, an exogenous increase in $q$ or $v$ would cause $T$ to rise and therefore would cause $\phi$ to fall. Note that if physicians engage in price discrimination according to patient characteristics such as race and income and these characteristics can be measured, they would be included in the $K$ vector in the price function. Note also that the first-order conditions for the optimal amounts of $q$ and $v$ obtained in Section $I$ are not altered, although $\phi$ is an endogenous variable. This follows because $T$ and therefore $\phi$ are held constant when the optimal a mount of $q$ or $v$ is selected. 
tion of price per visit or observed fee given in equation (4) and take natural logarithms:

$$
\ln p=\ln q+\ln \hat{p}
$$

Let the natural logarithm of the quality of pediatric care produced by physicians be a linear function of a vector $(X)$ of physicians' characteristics:

$$
\ln q=a X \text {. }
$$

Arguments in the $X$ vector affect productivity of physicians and include variables such as number of years of experience, type of specialty, board certification status, quality of medical school training, and memberships in professional societies. Substitution of equation (29) into equation (28) yields an hedonic fee function:

$$
\ln p=a X+\ln \hat{p}
$$

Estimation of equation (30) by regression methods allows one to compute both the natural logarithm of quality from the predicted value of fee for a given observation and a preliminary estimate of quality-adjusted price from the regression residual. These computations serve as inputs into the estimation of two-stage least-squares demand functions. A full discussion of the econometric methodology is contained in Goldman and Grossman (1976). Space limitations prevent us from incorporating this discussion in the present paper. Definitions of all variables in the hedonic fee function and an estimate of this function are presented in the Appendix.

The demand functions for quality and visits are specified as

$$
\begin{aligned}
\text { VISITS }= & b_{0}+b_{1} \text { QUALPRICE }+b_{2} \text { FAMINC } \\
& +b_{3} \text { TRFIXED }+b_{4} \mathrm{AC}+b_{5} \mathrm{NC}+b_{6} \mathrm{HO} \\
& +b_{7} \mathrm{HSI}+b_{8} \mathrm{HS} 2+b_{9} \mathrm{HS} 3+b_{10} \mathrm{SM} \\
\text { QUAL }= & c_{0}+c_{1} \text { QUALPRICE }+c_{2} \text { FAMINC } \\
& +c_{3} \text { TRFIXED }+c_{4} \mathrm{AC}+c_{5} \mathrm{NC}+c_{6} \mathrm{HO} \\
& +\mathrm{C}_{7} \mathrm{HSI}+c_{8} \mathrm{HS} 2+c_{9} \mathrm{HS} 3+c_{10} \mathrm{SM} .
\end{aligned}
$$

Table 3 contains definitions of the variables in these equations. In cases where the child saw more than one physician during the year, quality per visit is defined as a weighted average of quality of each source where the weights are the percentage of visits to that source. A preliminary estimate of quality-adjusted price is obtained directly from the hedonic price function when there is only one source. When there is more than one, the preliminary estimate is computed as

where

$$
\text { QUALPRICE }=\sum_{i=1}^{n} k_{i} \text { QUALPRICE }_{i}
$$

$$
k_{i}=\left(Q_{\text {UAL }}\right)\left(\operatorname{VISITS}_{i}\right) / \sum_{i=1}^{n}\left(\mathrm{QUAL}_{i}\right)\left(\operatorname{VISITS}_{i}\right)
$$


TABLE 3

Definition of Variables in Demand Functions

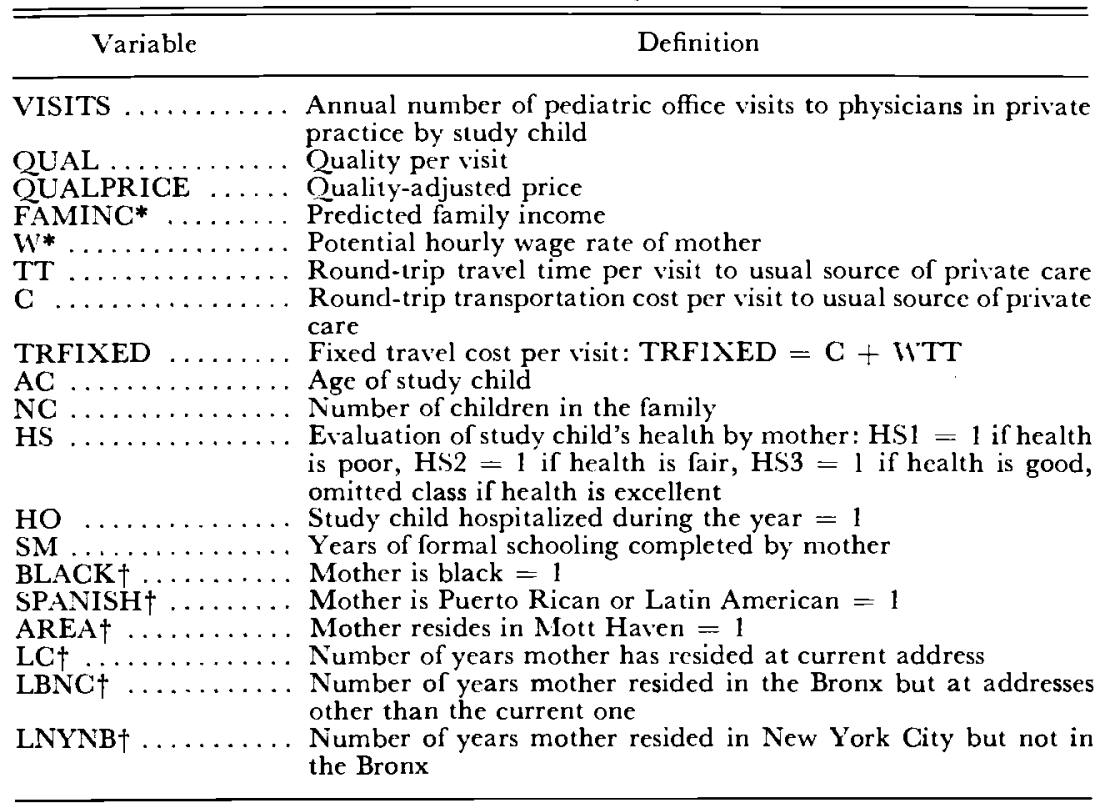

* See text for a more cletailed definition.

+ Predictor variable of quality-adjusted price in first stage.

As has been indicated previously, demand functions are estimated by two-stage least squares, with quality-adjusted price treated as an endogenous variable. This technique not only eliminates simultaneous equations bias but also reduces biases due to measurement error in the preliminary estimate of quality-adjusted price. In addition to the exogenous variables in the demand functions, the last six variables in table 3 serve as instrumental variables to predict quality-adjusted price in the first stage. Here it is assumed that these additional variables measure efficiency in search and the family's knowledge of the pediatric-care market. They might also reflect price discrimination by physicians due to patient characteristics. No information on price was obtained in the MD survey if the mother reported health insurance coverage for pediatric office visits, To examine the impact of insurance on the quantity-quality trade-off, we assume that the insured have a policy with a 25 percent coinsurance rate. Their quality-adjusted price is set equal to 25 percent of the mean qualityadjusted price in the uninsured sample. We have experimented with alternative coinsurance rates of 0,20 , and 50 percent and have found that the results in Section III are not sensitive to these alternative rates. ${ }^{13}$

${ }^{13}$ Since the MD survey preceded the enactment of Medicaid and private health insurance typically did not cover office visits to physicians in the mid-1960s, only 10 percent 
Besides the effect of quality-adjusted price, we emphasize empirically the impacts of fixed cost and income. There are no measures of waiting time and mother's actual or potential hourly wage rate in the MD survey. The wage is derived from Fuchs's (1968) calculations of hourly wage rates of women aged $20-34$ by race and years of formal schooling completed. ${ }^{14}$ The fixed-cost variable in the demand functions is fixed travel cost per visit (TRFIXED). ${ }^{15}$ It differs from the fixed-cost variable defined in Section I by the monetary value of waiting time (WTW): FIXED = TRFIXED + WTW. Given the linear demand specification, the regression coefficient of TRFIXED should equal that of WTW if both were entered as separate variables. Therefore, the coefficient of TRFIXED would be an unbiased estimate of the coefficient of FIXED if TRFIXED and WTW were uncorrelated. Employing an independent estimate of waiting time, we compute the fixed-cost elasticity based on the mean of FIXED and the slope coefficient of TRFIXED in Section III. ${ }^{16}$ Finally, the measure of permanent income used is based on a regression of reported family income on father's schooling, race, ethnicity, area of residence, and the presence of the father in the household.

\section{Empirical Estimates}

The second stages of two-stage least-squares estimates of demand functions for quality and visits are presented in table $4 .{ }^{17}$ Income has a positive regression coefficient in each demand curve and is statistically significant at conventional levels. As shown in table 5, A, the income elasticity of visits

of the sample families had health insurance for pediatric visits. Note that the technique for the estimation of demand functions would be identical with two-stage least squares if the insured were omitted. Since they are not excluded, it may be viewed as a "quasi" two-stage technique, al though we refer to the demand functions as two-stage least-squares estimates in Section III.

14 Even if some women did not work in the labor force, our procedure would be justified if the value of nonmarket time depended on race or schooling. The MD sample contains information on labor force sta tus of the mother, but there are not enough observations in the study sample to estimate separate demand functions by labor force status.

15 In cases where there is more than one usual source, travel time is defined as a weighted average of travel time to each source, where the weights are the percentage of visits to that source. A similar comment applies to transportation cost.

16 TRFIXED and WTW probably are positively correlated because both depend in part on the wage rate. Consequently, the slope coefficient of TRFIXED might overestimate that of FIXED. By computing fixed-cost elasticities at the mean of TRFIXED and at the mean of FIXED, we provide lower- and upper-limit estimates of the elasticity.

17 When two-stage least-squares estimation is employed, the ratios of regression coeffcients to their standard errors do not have Student's $t$-distribution but do have an asymptotic normal distribution. Therefore, the $t$-test is an asymptotic one. The unadjusted coefficients of multiple determination $\left(R^{2}\right)$ in table 3 should be interpreted with caution. We forced the $R^{2}$ to fall between zero and one by using the variance in predicted qualityadjusted price in computing them. We used this procedure to get a rough approximation of "explanatory power." 
TABLE 4

Two-Stage Least-Squares Estimates of Demand Curves FOR VISITS AND QUALITY

\begin{tabular}{|c|c|c|c|c|}
\hline \multirow[b]{2}{*}{ VARIABLE } & \multicolumn{2}{|c|}{ Demand Curve for Visits* } & \multicolumn{2}{|c|}{ Demand Curve for Quality $\dagger$} \\
\hline & $\begin{array}{l}\text { Regression } \\
\text { Coefficient }\end{array}$ & $\underset{t \text {-Ratio }}{\text { Asymptotic }}$ & $\begin{array}{l}\text { Regression } \\
\text { Coefficient }\end{array}$ & $\begin{array}{c}\text { Asymptotic } \\
t \text {-Ratio }\end{array}$ \\
\hline QUALPRICE $_{+} \ldots \ldots$ & -.071 & -.46 & -1.581 & -4.31 \\
\hline FAMINC ...... & .135 & 8.11 & .254 & 6.42 \\
\hline TRFIXED $\ldots \ldots \ldots$ & -.280 & -1.42 & .935 & 1.98 \\
\hline $\mathrm{AC} \ldots \ldots \ldots \ldots$ & -1.218 & -8.71 & .270 & .81 \\
\hline $\mathrm{NC} \ldots \ldots \ldots \ldots \ldots$ & -.604 & -2.14 & -.055 & -.08 \\
\hline $\mathrm{HO}$ & 1.920 & 2.49 & 4.709 & 2.56 \\
\hline$\ldots \ldots \ldots \ldots \ldots$ & .911 & .42 & 9.669 & 1.86 \\
\hline$\ldots \ldots \ldots \ldots \ldots$ & 3.468 & 3.81 & -1.310 & -.60 \\
\hline$\ldots \ldots \ldots \ldots \ldots$ & .203 & .39 & .079 & .06 \\
\hline $\mathrm{SM}, \ldots \ldots \ldots \ldots \ldots$ & .192 & 1.90 & -.317 & -1.32 \\
\hline CONSTANT $\ldots \ldots \ldots \ldots$ & -.696 & $\cdots$ & .948 & $\ldots$ \\
\hline$R^{2} \quad \ldots \ldots \ldots \ldots \ldots \ldots$ & .264 & $\ldots$ & .158 & $\cdots$ \\
\hline
\end{tabular}

NotE,_Sample size is 568. See table 3 for definitions of all variables.

* Dependent variable is annual number of pediatric visits to physicians in private practice.

$\dagger$ Dependent variable is quality per visit. All coefficients except constant are multiplied by 100

† Endogenous.

is much larger than the income elasticity of quality. When combined sample mean values of income, quality, and visits are used to compute these elasticities, the income elasticity of visits is 1.32 and the income elasticity of quality is 0.16 . Similar conclusions emerge when the computations are based on mean values of Mott Haven residents or mean values of Westchester residents.

The finding that visits are more responsive to income than quality might appear to be a counterintuitive one. Yet in our theoretical analysis we showed that the presence of a fixed-cost component in the total cost of a visit would tend to cause the ratio of the observed income elasticity of quality to the observed income elasticity of visits to be less than the corresponding ratio of pure income elasticities (see eq. [27]). Of course the income elasticities in table 5 are observed, rather than pure, income elasticities. In the sample, fixed travel cost accounts for 23 percent of the total cost of a visit exclusive of waiting cost on average. Using an independent figure on waiting time per visit from Aday and Andersen (1975), we estimate that the share of fixed cost in the total cost of a visit equals 33 percent. Therefore, the ratio of observed income elasticities would tend to fall short of the ratio of pure income elasticities unless the pure income elasticity of quality were one and one-half times as large as that of visits. In the special case in which pure inceme elasticities were the same, the observed income elasticity of quality would be smaller than that of visits.

According to the results in table 4, an increase in the fixed travel cost of a visit simultaneously reduces number of visits and increases quality per visit. These results support our hypothesis that an increase in fixed cost per 
TABLE 5

Estimates of Income, Uncompensated Price Elasticities, and Compensated Price Elasticities

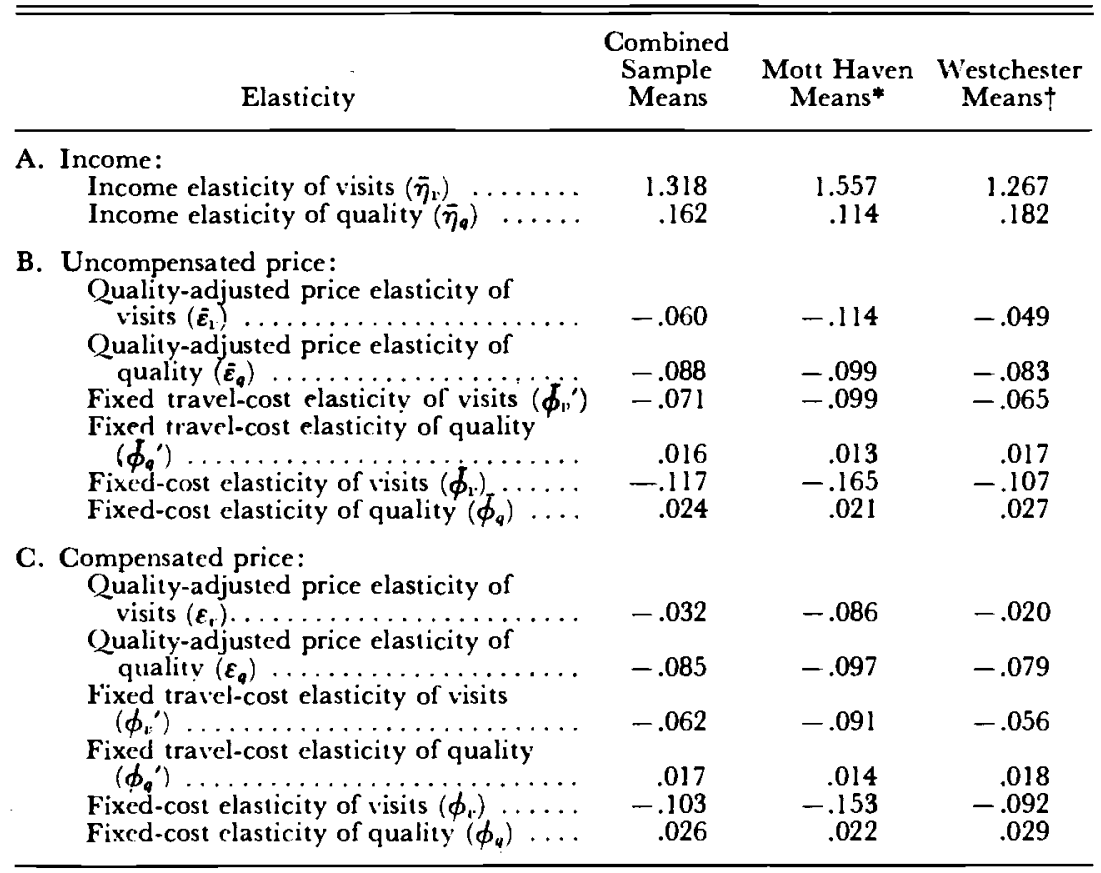

- Means are for 179 Mott Haven residents in the regressions in table 4.

$\dagger$ Means are for 389 Westchester residents in the regressions in table 4.

visit lowers the relative price of quality and leads consumers to substitute quality for visits. The coefficient of TRFIXED in the demand function for visits is statistically significant at the 8 percent level of confidence on a one-tailed test. The coefficient of the same variable in the demand function for quality is significant at the 2.5 percent level of confidence on a one-tailed test. The estimated fixed cost effects are not due to multicollinearity between TRFIXED and mother's schooling. When the latter variable is omitted from the regressions, the coefficient of TRFIXED in the visit function equals $-0.268(t=-1.35)$. The corresponding coefficient in the quality function equals $0.915(t=1.94)$.

Quality-adjusted price has a negative and statistically significant regression coefficient in the demand curve for quality. The same variable has an insignificant negative regression coefficient in the demand curve for visits. In our theoretical analysis we showed that an increase in qualityadjusted price raises the relative price of quality and causes the ratio of quality to visits to fall. If one accepts the null hypothesis that qualityadjusted price has no impact on visits, then the findings are consistent with this prediction. 
Since the point estimate of the effect of quality-adjusted price on visits is negative, it is worth examining the behavior of the quality-visit ratio based on the quality-adjusted price elasticities of quality and visits $\left(\bar{\varepsilon}_{q}\right.$ and $\left.\bar{\varepsilon}_{v}\right)$. This analysis also enables us to explore the proposition that the absolute value of the fixed-cost elasticity of visits should exceed the absolute value of the quality-adjusted price elasticity of visits. According to the uncompensated (money income constant) price elasticities computed at combined sample means in table $5, \mathrm{~B},\left|\bar{\varepsilon}_{q}\right|$ exceeds $\left|\bar{\varepsilon}_{v}\right|(0.088$ vs. 0.060 ). Moreover, the absolute value of the fixed travel-cost elasticity $\left(\left|\bar{\phi}_{v}^{\prime}\right|=0.071\right)$ also exceeds $\left|\bar{\varepsilon}_{v}\right|$. Similar conclusions emerge when Westchester means are employed to compute the elasticities. When, however, Mott Haven means are employed, $\left|\bar{\varepsilon}_{\boldsymbol{v}}\right|$ exceeds both $\left|\bar{\varepsilon}_{\boldsymbol{q}}\right|$ and $\left|\bar{\phi}_{v}^{\prime}\right|$.

As was indicated previously, the fixed travel-cost elasticities may underestimate the relevant fixed-cost elasticities $\left(\Phi_{v}\right.$ and $\left.\phi_{q}\right)$ due to the absence of a measure of waiting time per visit in the MD survey. Using Aday and Andersen's (1975) estimate of waiting time per visit, we have calculated these elasticities by using the mean of FIXED and the regression coefficient of TRFIXED. This raises the absolute value of the fixed cost elasticity of visits from 0.060 to 0.117 and raises the numerical value of the corresponding elasticity of quality from 0.016 to 0.024 at the combined sample means. At Mott Haven, Westchester, or combined sample means, $\left|\bar{\phi}_{v}\right|$ exceeds $\left|\bar{\varepsilon}_{v}\right|$.

Our predictions concerning the relative magnitudes of price elasticities pertain to compensated (utility or real income constant) rather than to uncompensated price elasticities. Estimates of compensated price elasticities are shown in table $5, \mathrm{C}$. These estimates are derived from equations $(23)-(26)$ in table 2 . The figures in the table provide dramatic evidence in favor of all our hypotheses. Regardless of the means on which the elasticities are based, $\left|\varepsilon_{q}\right|$ is greater than $\left|\varepsilon_{v}\right|$. In addition, both $\left|\phi_{v}^{\prime}\right|$ and $\left|\phi_{v}\right|$ are greater than $\left|\varepsilon_{v}\right|$. The comparisons in table 5, C differ somewhat from those in 5, B because the income elasticity of visits is much larger than that of quality. Moreover, the share of total pediatric cost in income, while small in an absolute sense, is approximately twice as large as the share of total fixed cost.

Several recent studies have established the importance of mother's schooling as a positive correlate of efficiency in the production of healthy children. ${ }^{18}$ Michael (1972) has described the impact of a "neutral" improvement in efficiency in the production of all household commodities. ${ }^{19}$ With money income held constant, the demand for inputs associated with a given commodity would rise, fall, or remain the same as the income

18 See, for example, Friedman and Leibowitz 1975 and Grossman 1975.

19 A neutral improvement in efficiency is one that raises all marginal products in all production functions by the same percentage. The analysis of the role of mother's schooling would have to be modified if the improvement in efficiency associated with it were not neutral. 
elasticity of the commodity were greater than, less than, or equal to one. We have found that the income elasticity of visits is greater than one and the income elasticity of quality is less than one. Therefore, an increase in mother's schooling should increase visits and lower quality, which is consistent with the schooling coefficients reported in table $4 .^{20}$

\section{Summary and Implications}

In this paper we have developed a model of quantity-quality substitution and have used it to study the demand for pediatric care. The power of our theoretical model lies in its ability to make predictions about magnitudes, as well as signs of various effects. Compare our approach with that of others. Inman (1976) regresses number of visits on the shadow price of a visit $\left(\pi_{v}\right)$ and other variables but omits the shadow price of quality $\left(\pi_{q}\right)$. Since $\pi_{v}$ and $\pi_{q}$ are likely to be positively correlated and since an increase in $\pi_{q}$ should raise visits $(v)$, his calculation of the effect of $\pi_{v}$ on $v$ probably is biased downward in absolute value. Fuchs and Kramer (1972), Newhouse and Phelps (1974, 1976), and Feldman (1975) regress the product of quality and visits on quality-adjusted price. This approach does not distinguish variations in the ratio of visits to quality due to variations in income, fixed cost, or quality-adjusted price.

Specifically, we predict that the ratio of quality to visits falls as income and quality-adjusted price rise, and rises as the fixed cost of a visit rises. Moreover, visits are more responsive to a 1 percent change in fixed cost than to a 1 percent change in quality-adjusted price. These predictions are supported by the empirical analysis. They hold for price elasticities whether money income or real income (utility) is held constant.

Consider the implications of the foregoing analysis for government policies designed to increase the utilization of physicians' services, such as national health insurance or direct cash subsidies. Various proposals for comprehensive national health insurance have been pending in the United States Congress for the past 8 years. Recently, it has been recommended that coverage be limited to maternal and pediatric care. ${ }^{21}$ Since our findings indicate that private pediatric visits are very sensitive to income, it might be more efficient to increase these visits by means of direct cash subsidies rather than by means of national health insurance. According

${ }^{20}$ For a discussion of the effects of other variables in the demand functions, see Goldman and Grossman (1976).

${ }^{21}$ See the Maternal and Child Comprehensive Health Bill of 1976 introduced by Congressman James H. Scheuer of New York. A full treatment of the merits of such legislation would take account of the impact of pediatric care on health outcomes and of the effect of the legislation on the rate of inflation in the medical care market. This treatment is beyond our scope, and we take as given the goal of increased utilization of pediatric care. It should also be realized that our results pertain to the demand for pediatric care by a relatively low income sample of New York City residents. Although they might not generalize to the behavior of all families in the population, they are very relevant in the analysis of government policies that are aimed at the urban poor. 
to our results, such a policy would lower the ratio of quality to visits demanded. If national health insurance is adopted, then the form of the insurance might have a significant impact on the quantity-quality mix demanded. A policy that pays a fixed percentage of the fee of a visit (that is, a policy with a positive coinsurance rate) would lower quality-adjusted price and cause a substitution of quality for visits. A policy that pays a fixed amount of the fee of a visit may be viewed as a policy that reduces the fixed cost of a visit. Therefore, such a policy would cause a substitution toward visits and away from quality. The relative merits of alternative forms of national health insurance depend in part on the relative effects of quality and visits on child health outcomes. This topic deserves high priority on an agenda for future research.

\section{Appendix}

Table Al contains definitions of all variables in the hedonic fee function and the estimated function. There is no a priori reason to choose a particular specification of the hedonic fee function. We have experimented with several and have chosen the semilogarithmic function because of its widespread use in the literature (e.g., Griliches 1971). The use of a linear function does not alter our basic results. Moreover, demand functions based on alternative specifications of the hedonic fee function do not differ from those reported in the text.

TABLE A1

Ordinary least Squares Estimate of Hedonic Price Function for Pediatric Care

\begin{tabular}{|c|c|c|c|c|}
\hline \multirow[b]{2}{*}{ VARIABLE } & \multicolumn{2}{|c|}{ Mott Haven } & \multicolumn{2}{|c|}{ WESTCHESTER } \\
\hline & $\begin{array}{l}\text { Regression } \\
\text { Coefficient }\end{array}$ & $t$-Ratio & $\begin{array}{l}\text { Regression } \\
\text { Coefficient }\end{array}$ & t-Ratio \\
\hline $\begin{array}{l}\text { Years since physician gradu- } \\
\text { ated from medical school } \\
\text { (experience) } \ldots \ldots \ldots \ldots \ldots \\
\text { Square of experience } \ldots \ldots \ldots\end{array}$ & -.017 & $\begin{array}{r}-4.37 \\
4.08\end{array}$ & $\begin{aligned}-.005 \\
.0001\end{aligned}$ & $\begin{array}{r}-1.66 \\
1.58\end{array}$ \\
\hline $\begin{array}{l}\text { Primary practice in pediatrics } \\
=1\end{array}$ & .015 & .18 & .263 & 5.79 \\
\hline medicine $=1 * \ldots \ldots \ldots$ & -.020 & -.21 & .051 & .69 \\
\hline gynecology $=1 * \ldots \ldots$ & .340 & 3.29 & .041 & .43 \\
\hline$=1 * \ldots \ldots \ldots \ldots \ldots$ & -.054 & -.32 & .102 & .92 \\
\hline $\begin{array}{l}\text { Primary practice in another } \\
\text { specialty }=1\end{array}$ & .120 & 1.03 & -.017 & -.24 \\
\hline $\begin{array}{l}\text { Board certification in pedia- } \\
\quad \text { trics }=1 \ldots \ldots \ldots \ldots \ldots \\
\text { Board certification in internal }\end{array}$ & .247 & 4.18 & .135 & 3.96 \\
\hline $\begin{array}{l}\text { medicine }=1 \ldots \ldots \ldots \ldots \\
\text { Board certification in }\end{array}$ & -.079 & -.44 & .196 & .81 \\
\hline $\begin{array}{l}\text { trics-gynecology }=1 \ldots \\
\text { Board certification in surgery }\end{array}$ & -.006 & -.03 & -.057 & -.55 \\
\hline $\begin{array}{l}\quad=1 \ldots \ldots \ldots \ldots \ldots \ldots \\
\text { Board certification in another }\end{array}$ & .166 & 1.03 & .775 & 3.14 \\
\hline specialty $=1 \ldots \ldots \ldots$ & .169 & 1.48 & .095 & 1.15 \\
\hline
\end{tabular}


TABLE Al (Continucd)

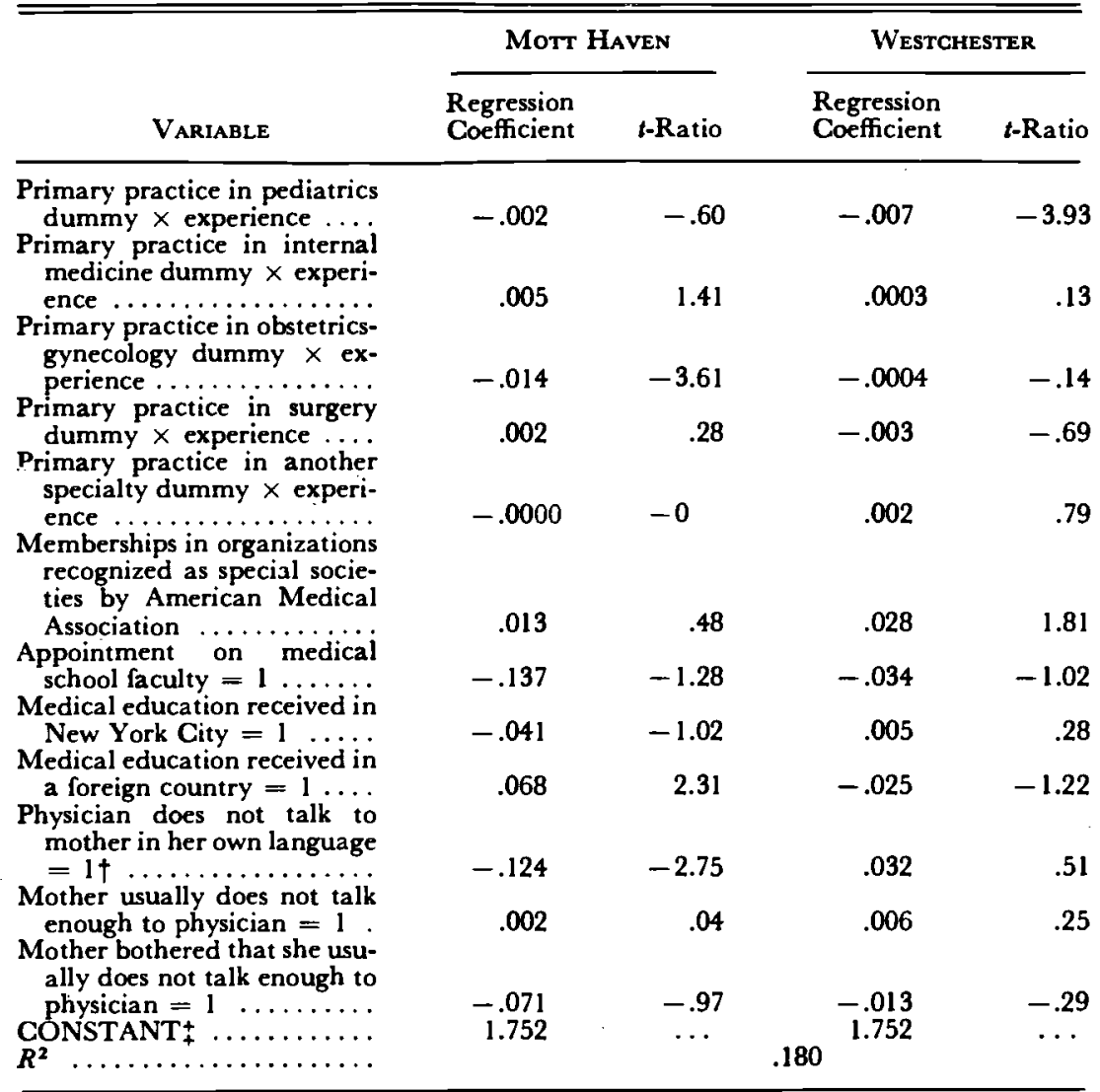

NotE.-Dependent variable is natural logarithm of usual fee charged by physician for a pediatric office visit. Sample size is 1,$687 ; R^{2}$ is unadjusted coefficient of multiple determination.

- Omitled class is primary practice in general practice.

t Only mothers who do not speak English were asked whether the physician talks to them in their own language.

: Constrained to be the same in the two areas.

The fee regression is run across all usual sources of pediatric care reported by mothers in the study and control groups of the MD survey. The usual source, as opposed to the actual source, is the physician who normally provides pediatric care to the family. ${ }^{22}$ If each mother reported a single usual source and each mother used a different physician, the number of usual sources, number of physicians, and number of families in the regression all would be equal. In fact, these three variables are not equal because some mothers indicated more than one usual source and different mothers took their children to the same physician. In the actual

22 Mothers of children in the study group were interviewed at least bi-monthly during an entire year, while mothers of children in the control group were interviewed only once. Members of the control group are excluded from the demand functions because the dependent variable in the demand curve for visits is annual number of pediatric visits. Since mothers in the control sample were interviewed only once and were asked about visits in the last month, an estima te of annual visits for them would be subject to a much larger variance than an estimate of annual visits for the study group. 
regression there are 443 physicians who account for 1,687 usual sources of care (observations). ${ }^{23}$ Fee information was not obtained if the mother said that part or all of the fee was covered by health insurance. Therefore, these observations are excluded from the regression.

The independent variables in the regression are designed to measure variations in productivity among physicians or variations in the quality of pediatric services that they produce. Productivity differences are traced in turn to experience (age), vintage, and model effects. Since vintage and experience effects may differ by specialty, interaction terms between number of years since graduation from medical school and each of the five specialties are used as independent variables. The first 21 variables in the fee function are used to capture experience, model, and vintage effects and are taken from the American Medical Association and New York State medical directories. The last three variables are entered to capture that part of the demand for pediatric care that is, more properly, a demand for information by mothers about the state of health of their children. Mothers should be willing to pay price premiums to physicians who convey relatively large amounts of information. In computing the fee function we allow all regression coefficients except the constant term to vary by area of residence (Mott Haven or Westchester). This procedure is adopted because of Goldman's (1975) evidence that each area constitutes a local market for medical care. ${ }^{24}$

${ }^{23}$ A justification for the usual source, rather than the physician, as the basic unit of observation is that more weight is given in the determination of quality to the characteristics of physicians who provide relatively large amounts of pediatric care. Our procedure is equivalent to the estimation of an aggregate fee function in which each observation (physician) is weighted by the square root of the number of patients who saw that physician.

24 Detailed discussions of the role of each variable in the hedonic fee function are contained in Steinwald and Sloan (1974) and Goldman (1975). The specific form of the fee function that we estimate is

$$
\ln \text { PRICE }=a_{0}+\sum_{j=1}^{2} \sum_{i=1}^{24} a_{i j} X_{i j} D_{j}+u,
$$

where $D_{1}$ equals one for Mott Haven residents and zero for Westchester residents, $D_{2}$ equals zero for Mott Haven residents and one for Westchester residents, $X_{i 1}$ or $X_{12}$ denotes one of the 24 independent variables in table $\mathrm{Al}$, and $u$ is the regression residual associated with a given observation. The regression coefficients in table Al are used to compute quality (QUAL) and the preliminary estimate of quality-adjusted price (QUALPRICE) as

$$
\begin{aligned}
& \ln \text { QUAL }=\sum_{j=-1}^{2} \sum_{i=1}^{24} a_{i j} X_{i j} D_{j}, \\
& \ln \text { QUALPRICE }=a_{0}+u .
\end{aligned}
$$

The inclusion of the regression constant $\left(a_{0}\right)$ in the logarithm of quality-adjusted price is consistent with the view that quality is a units-free index, while quality-adjusted price has the same units as observed price. Price and income elasticities of demand would not be altered if the intercept were treated in a different manner. We constrain the regression constant to be the same in each area because we include area of residence as an exogenous argument of the quality-adjusted price function (see n. 12). Therefore, a dummy variable distinguishing market areas is employed as an instrumental variable in the estimation of demand functions. As we show in Goldman and Grossman (1976), such variables should be excluded from the hedonic fee function. We have experimented with alternative treatments of the constant term. When it is not constrained to be the same in each area, the regression coefficients are not significantly different from those reported in table A1. As would be expected, demand functions estimated with this alternative fee function are nearly identical with those presented in Section III. For discussions of the results in table A1, see Goldman (1975) and Goldman and Grossman (1976). 


\section{References}

Acton, Jan P. "Nonmonetary Factors in the Demand for Medical Services: Some Empirical Evidence." J.P.E. 83, no. 3 (June 1975) : 595-614.

- "Demand for Health Care among the Urban Poor, with Special Emphasis on the Role of Time." In The Role of Health Insurance in the Health Services Sector, edited by Richard N. Rosett. New York: Neale W'atson Acad. Publication (for Nat. Bur. Econ. Res.), 1976.

Aday, Lu Ann, and Andersen, Ronald. Development of Indices of Access to Medical Care. Ann Arbor, Mich.: Health Admin., 1975.

Allen, Roy G. D. Mathematical Analysis for Economists. New York: St. Martin's, 1964.

Becker, Gary S., and Lewis, H. Gregg. "On the Interaction between the Quantity and Quality of Children." In New Economic Approaches to Fertility, edited by Theodore $W$. Schultz. Proceedings of a conference sponsored by the National Bureau of Economic Research and the Population Council. J.P.E. 81, no. 2, pt. 2 (March/April 1973): S279-S288.

Cowling, Keith, and Rayner, A. J. "Price, Quality and Market Share." J.P.E. 78, no. 6 (November/December 1970): 1292-1309.

Feldman, Roger. "Price and Quality Differences in the Physicians' Service Market." Presented at the annual meeting of the Allied Social Science Associations, Dallas, December 1975.

Friedman, Bernard, and Leibowitz, Arleen. "The Bequest Motive in Human Capital and the Health Care of Children." Unpublished paper. Brown Univ., Dept. Econ., 1975.

Fuchs, Victor R. The Service Economy. New York: Columbia Univ. Press (for Nat. Bur. Econ. Res.), 1968.

Fuchs, Victor R., and Kramer, Marcia J. Determinants of Expenditures for Physicians' Services in the United States, 1948-68. Rockville, Md., and New York: Nat. Center Health Services Res. and Development and Nat. Bur. Econ. Res., 1972.

Goldman, Fred. "An Economic Analysis of Child Health." Ph.D. dissertation, City Univ. New York, 1975.

Goldman, Fred, and Grossman, Michael. "The Demand for Pediatric Care: An Hedonic Approach." NBER Working Paper no. 134, April 1976.

Goldman, Steven M., and Uzawa, Hirofumi. "A Note on Separability in Demand Analysis." Econometrica 32, no. 3 (July 1964) : 387-98.

Griliches, Zvi. "Hedonic Price Indexes for Automobiles: An Econometric Analysis of Quality Change." In Government Price Statistics, Hearings, U.S. Congress, Joint Economic Committee. Washington: Government Printing Office, 1961.

- ed. Price Indexes and Quality Change: Studies in New Methods of Measurement. Cambridge, Mass.: Harvard Univ. Press, 1971.

Grossman, Michael. The Demand for Health: $A$ Theoretical and Empirical Investigation. New York: Columbia Univ. Press (for Nat. Bur. Econ. Res.), 1972.

. "The Correlation between Health and Schooling." In Household Production and Consumption, edited by Nestor E. Terleckyj. New York: Columbia Univ. Press (for Nat. Bur. Econ. Res.), 1975.

Holtmann, Alphonse G., and Olsen, E. Odgers, Jr. "The Determinants of the Demand for Physician Visits in a Consumer's Utility Model." Unpublished paper. State Univ. New York at Binghamton, Dept. Econ., 1974.

Houthakker, Hendrik S. "Compensated Changes in Quantities and Qualities Consumed." Rev. Econ. Studies 19, no. 3 (1952-53) : 155-64.

Inman, Robert P. "The Family Provision of Children's Health: An Economic Analysis." In The Role of Health Insurance in the Health Services Sector, edited by 
Richard N. Rosett. New York: Neale Watson Acad. Publication (for Nat. Bur. Econ. Res.), 1976.

King, A. Thomas. "The Demand for Housing : Integrating the Roles of Journeyto-Work, Neighborhood Quality, and Prices." In Household Production and Consumption, edited by Nestor E. Terleckyj. New York: Columbia Univ: Press (for Nat. Bur. Econ. Res.), 1975.

Michael, Robert T. The Effect of Education on Efficiency in Consumption. New York: Columbia Univ. Press (for Nat. Bur. Econ. Res.), 1972.

Muth, Richard F. "Household Production and Consumer Demand Functions." Econometrica 34, no. 3 (July 1966): 699-708.

Cities and Housing; the Spatial Pattern of Urban Residential Land Use. Chicago: Univ. Chicago Press, 1969.

Newhouse, Joseph P., and Phelps, Charles E. "Price and Income Elasticities for Medical Care Services." In The Economics of Health and Medical Care, edited by Mark Perlman. London: Macmillan, 1974.

- "New Estimates of Price and Income Elasticites of Medical Care Services." In The Role of Health Insurance in the Health Services Sector, edited by Richard N. Rosett. New York: Neale Watson Acad. Publication (for Nat. Bur. Econ. Res.), 1976.

Newhouse, Joseph P., and Sloan, Frank A. "Physician Pricing: Monopolistic or Competitive: Reply." Southern Econ. J. 38, no. 4 (April 1972) : 577-80.

Nichols, D.; Smolensky, E.; and Tideman, T. N. "Discrimination by Waiting Time in Merit Goods." A.E.R. 61, no. 3, pt. 1 (June 1971): 312-23.

Ohta, Makoto, and Griliches, Zvi. "Automobile Prices Revisited: Extensions of the Hedonic Hypothesis." In Household Production and Consumption, edited by Nestor E. Terleckyj. New York: Columbia Univ. Press (for Nat. Bur. Econ. Res.), 1975.

Phelps, Charles E. "Effects of Insurance on Demand for Medical Care." In Equity in Health Services: Empirical Analyses in Social Policy, edited by Ronald Andersen, Joanna Kravits, and Odin W. Anderson. Cambridge, Mass. : Ballinger, 1975.

Rosen, Sherwin. "Short-Run Employment Variation on Class I-Railroads in the U.S., 1947-1963." Econometrica 36, nos. 3-4 (July-October 1968) : 511-29.

- "Hedonic Prices and Implicit Markets: Product Differentiation in Pure Competition." J.P.E. 82, no. 1 (January/February 1974): 34-55.

Steinwald, Bruce, and Sloan, Frank A. "Determinants of Physicians' Fees." J. Bus. 47, no: 4 (October 1974): 493-511.

Straszheim, Mahlon R. An Econometric Analysis of the Urban Housing Market. New York: Columbia Univ. Press (for Nat. Bur. Econ. Res.), 1975.

Theil, Henri. "Qualities, Prices and Budget Enquiries." Rev. Econ. Studies 19, no. 3 (1952-53): 129-47.

Triplett, Jack E. The Theory of Hedonic Quality Measurement and Its Use in Price Indexes. BLS Staff Paper no. 6. Washington: Dept. Labor, Bur. Labor Statis., 1971.

Willis, Robert. "A New Approach to the Economic Theory of Fertility Behavior." In New Economic Approaches to Fertility, edited by Theodore W. Schultz. Proceedings of a conference sponsored by the National Bureau of Economic Research and the Population Council. J.P.E. 81, no. 2, pt. 2 (March/April 1973): S14S64. 